\title{
Impaired $\beta$-Amyloid Secretion in Alzheimer's Disease Pathogenesis
}

\author{
Davide Tampellini, ${ }^{1,2}$ Nawreen Rahman, ${ }^{1}$ Michael T. Lin, ${ }^{1}$ Estibaliz Capetillo-Zarate, ${ }^{1}$ and Gunnar K. Gouras ${ }^{1,2,3}$ \\ ${ }^{1}$ Department of Neurology and Neuroscience, Weill Cornell Medical College, New York, New York 10065, ${ }^{2}$ Department of Experimental Medical Science, \\ Wallenberg Neuroscience Center, Lund University, 22184 Lund, Sweden, and ${ }^{3}$ Rockefeller University, New York, New York 10065
}

A central question in Alzheimer's disease $(\mathrm{AD})$ research is what role $\beta$-amyloid peptide $(\mathrm{A} \beta)$ plays in synaptic dysfunction. Synaptic activity increases $\mathrm{A} \beta$ secretion, potentially inhibiting synapses, but also decreases intraneuronal $\mathrm{A} \beta$, protecting synapses. We now show that levels of secreted $\mathrm{A} \beta$ fall with time in culture in neurons of $\mathrm{AD}$-transgenic mice, but not wild-type mice. Moreover, the ability of synaptic activity to elevate secreted $\mathrm{A} \beta$ and reduce intraneuronal $\mathrm{A} \beta$ becomes impaired in $\mathrm{AD}$-transgenic but not wild-type neurons with time in culture. We demonstrate that synaptic activity promotes an increase in the $\mathrm{A} \beta$-degrading protease neprilysin at the cell surface and a concomitant increase in colocalization with $\mathrm{A} \beta 42$. Remarkably, AD-transgenic but not wild-type neurons show reduced levels of neprilysin with time in culture. This impaired ability to secrete $\mathrm{A} \beta$ and reduce intraneuronal $\mathrm{A} \beta$ has important implications for the pathogenesis and treatment of $\mathrm{AD}$.

\section{Introduction}

A defining neuropathological feature of Alzheimer's disease (AD) is the aberrant accumulation of $\beta$-amyloid peptide $(\mathrm{A} \beta)$. $\mathrm{A} \beta$ accumulation can lead to alterations in synapses and memory (Selkoe, 2002; Almeida et al., 2005; Hsieh et al., 2006). The site(s) and mechanism(s) whereby $A \beta$ initiates dysfunction of synapses in $\mathrm{AD}$ are of major interest. Secreted, extracellular $\mathrm{A} \beta$ has traditionally been viewed as the source of $A \beta$-induced toxicity to synapses in $\mathrm{AD}$, since addition of $\mathrm{A} \beta 1-42$ impairs synaptic function (Cleary et al., 2005; Shankar et al., 2008). In contrast, picomolar levels of extracellular $A \beta$ were recently shown to enhance synaptic plasticity (Puzzo et al., 2008). Remarkably, synaptic activity increases levels of secreted, extracellular $\mathrm{A} \beta$ (Kamenetz et al., 2003; Cirrito et al., 2005). Since the default network of the brain is particularly prone to the development of $\mathrm{AD}$, it has been hypothesized that brain regions with the highest baseline metabolic activity are prone to $\mathrm{AD}$ because of high amounts of secreted $\mathrm{A} \beta$ (Cirrito et al., 2008; Palop and Mucke, 2010). However, it is unclear why such elevated levels of secreted $A \beta$ from default network activity cause problems only with aging. Moreover, atrisk individuals for $\mathrm{AD}$ show reduced brain activity decades before clinical symptoms (Reiman et al., 2004), which might predict

Received June 14, 2011; revised Aug. 22, 2011; accepted Sept. 9, 2011.

Author contributions: D.T. and G.K.G. designed research; D.T., N.R., and E.C.Z. performed research; D.T., N.R., and G.K.G. analyzed data; D.T., M.T.L., and G.K.G. wrote the paper.

This work was supported by an Alzheimer's Association New Investigator Award (D.T.) and Zenith Award (G.K.G.), National Institute of Health Grants AG027140, AG028174, AG09464 (G.K.G.), and AG020729 (M.T.L.), and the Strong Research Environment Multipark (Multidisciplinary research in Parkinson's disease at Lund University). We thank Fangmin Yu and Eleanor Reilly for technical support.

The authors declare no competing financial interests.

Correspondence should be addressed to Gunnar K. Gouras, Department of Experimental Medical Science, Wallenberg Neuroscience Center, BMC B12, Lund University, Sölvegatan 19, 22184 Lund, Sweden. E-mail: gunnar.gouras@med.lu.se.

DOI:10.1523/JNEUROSCI.2986-11.2011

Copyright $\odot 2011$ the authors $\quad 0270-6474 / 11 / 3115384-07 \$ 15.00 / 0$ reduced $\mathrm{A} \beta$ secretion. There is increasing support for an alternative scenario focusing on aberrant intracellular accumulation of $\mathrm{A} \beta$ within vulnerable neurons (Gouras et al., 2010). In fact, we recently demonstrated that $\mathrm{A} \beta$-related synapse damage and memory impairment in $\mathrm{AD}$-transgenic mice correlated with this intracellular pool of $\mathrm{A} \beta$ but not with plaques (Tampellini et al., 2010).

We now provide evidence for reduced $\mathrm{A} \beta$ secretion with time in culture in $\mathrm{AD}$-transgenic but not wild-type neurons. Furthermore, we show that synaptic activity is able to reduce levels of intracellular $\mathrm{A} \beta$ in $\mathrm{AD}$-transgenic neurons at 12 but not at 19 days in vitro (DIV). We demonstrate that levels of neprilysin are reduced in $\mathrm{AD}$-transgenic but not wild-type neurons with time in culture. Finally, we provide mechanistic evidence consistent with neprilysin leading to degradation of $\mathrm{A} \beta 42$ at the cell surface with synaptic activity.

\section{Materials and Methods}

Neuronal cultures. Primary neuronal cultures were prepared from cortices and hippocampi of embryonic day $15 \mathrm{Tg} 2576$ (AD-transgenic) (Hsiao et al., 1996) and wild-type littermate mouse embryos, as described previously (Tampellini et al., 2009). Tg2576 male and wild-type female mice (Jackson Laboratories) were bred to generate the embryos. Mice were used in accordance with the NIH Guide for the Care and Use of Laboratory Animals.

Antibodies. For immunofluorescence, the following antibodies were used.: neprilysin (H-321; Santa Cruz Biotechnology), early endosomal antigen-1 (BD Transduction Laboratories), tumor susceptibility gene 101 (GeneTex), amyloid precursor protein (APP) intracellular domain (AICD; Covance), postsynaptic density-95 (PSD-95; Millipore), A $\beta 42$ (C terminus; Covance). For Western blot, the following antibodies were used: human-specific A $\beta / A P P 6 E 10$ (Covance), murine and human A $\beta /$ APP 4G8 (Covance), rabbit polyclonal APP (C terminus) 369, phosphoCaMKII (Millipore), total CaMKII (Millipore). Secondary antibodies were conjugated to Alexa Fluor-488 or -546 (Invitrogen) or horseradish peroxidase (GE Healthcare). 
A

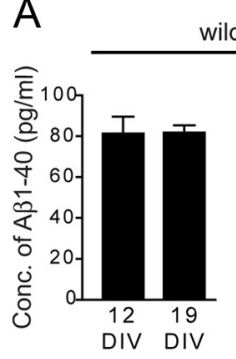

vild-type

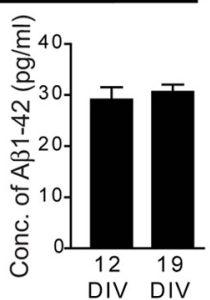

B
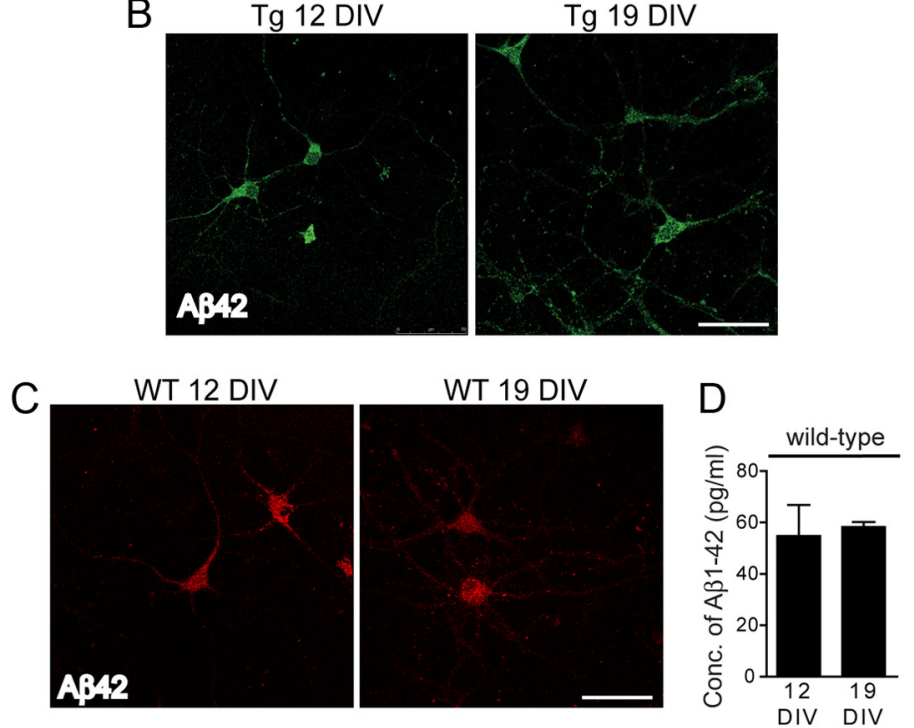

E
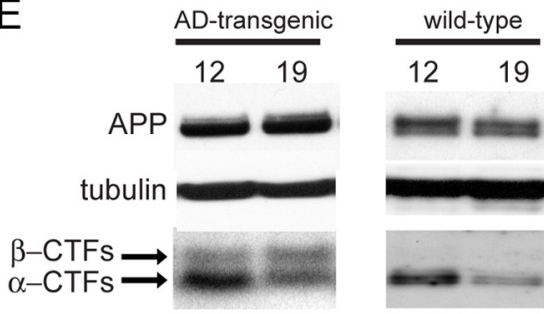

longer exposure
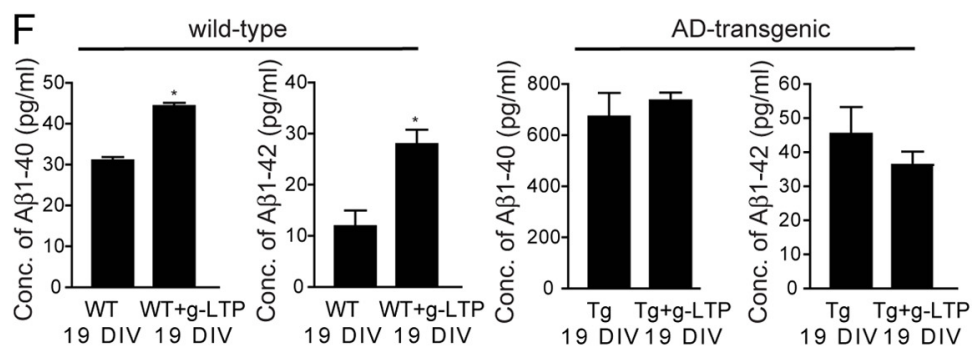

Figure 1. Decreased $A \beta$ secretion in AD-transgenic (Tg) but not wild-type (WT) neurons with time in culture. $A$, Levels of $A \beta 1-40$ and $A \beta 1-42$ were assayed by ELISA in media of $A D$-transgenic or wild-type neurons. While wild-type neurons secrete comparable amounts of $A \beta$ peptides at 12 and 19 DIV ( $n=6$; left), AD-transgenic neurons showed decreased levels of $A \beta 1-40$ and $A \beta 1-42$ in media at 19 compared with 12 DIV ( $n=10$; ${ }^{*} p<0.05,{ }^{* *} p<0.01$; right). $\boldsymbol{B}$, Levels of intraneuronal $A \beta 42$ were increased by $46 \pm 17 \%$ in AD-transgenic neurites at 19 compared with 12 DIV $(n=4 ; p<0.05)$. C, D, Levels of intraneuronal $A \beta 42$ were unchanged in wild-type neurons at 19 compared with 12 DIV, as quantified by confocal immunofluorescence $(\boldsymbol{C})$ and ELISA $(\boldsymbol{D})(n=4)$. $\boldsymbol{E}$, Left, Levels of $\alpha$ CTFs were decreased by $52 \pm 2 \%$, while levels of $\beta$ CTFs and full-length APP were unchanged in AD-transgenic neurons at 19 compared with 12 DIV $(n=4 ; p<0.01)$. Right, Levels of $\alpha$ CTFs were decreased by $32 \pm 9 \%(n=5 ; p<0.05)$, while levels of $\beta$ CTFs (longer exposure) showed a trend for a $49 \pm 16 \%$ decrease $(p=0.074)$ in wild-type neurons at 19 compared with 12 DIV.F, At 19 DIV, AD-transgenic neurons failed to enhance secretion of both $A \beta 1-40$ and $A \beta 1-42$ during $g$-LTP ( $n=6$, right). In contrast, wild-type neurons were still able to increase $A \beta 1-40$ and $A \beta 1-42$ secretion during $g$-LTP ( $n=4 ;{ }^{*} p<0.05$, left). Conc., Concentration. Scale bars, $50 \mu \mathrm{m}$.
Treatments. For glycine-induced long term potentiation (g-LTP), neurons were treated as described previously (Tampellini et al., 2009). In experiments on neprilysin and $\mathrm{A} \beta 42$ surface colocalization during g-LTP stimulation, 50 $\mu \mathrm{M}$ thiorphan was added to neurons during the 15 min incubation with or without glycine; 50 $\mu \mathrm{M}$ thiorphan was then added during the following $1 \mathrm{~h}$ chase to prevent $\mathrm{A} \beta$ degradation.

ELISA analysis. To measure $\mathrm{A} \beta$ secretion from primary neurons (10 $\mathrm{cm}$ dish) at steady state, media were replaced with $1 \mathrm{ml}$ of fresh neurobasal medium and collected after $5 \mathrm{~h}$. To measure $\mathrm{A} \beta$ secretion with or without g-LTP, LTP buffer was collected after the $1 \mathrm{~h}$ chase. Concentrations of $\mathrm{A} \beta 1-40$ and $\mathrm{A} \beta 1-42$ were measured using the respective ELISA kits (Biosource) for mouse (wild-type neurons) or human (AD-transgenic neurons) $\mathrm{A} \beta$.

Western blot. Neuron lysates were prepared as described previously (Tampellini et al., 2009). Membranes were immunoblotted with antibodies $6 \mathrm{E} 10$ or 369 , and intensities were quantified using Scion Image software (NIH).

Immunofluorescence. Immunofluorescence and its quantification were performed as described previously (Tampellini et al., 2009). Localization of surface neprilysin with $\mathrm{A} \beta 42$ and subcellular markers was determined using a colocalization algorithm (Leica Application Suite 1.8.2 software). To count AICD-positive nuclei, all nuclei were marked with Hoechst stain. Counts of AICD-positive and total nuclei were performed with MetaMorph on 6-10 fields per coverslip at $20 \times$ magnification.

Statistical analysis. Statistical comparisons were made using two-tailed unpaired $t$ tests with significance placed at $p<0.05$.

\section{Results}

We previously reported progressive intraneuronal $\mathrm{A} \beta 42$ accumulation, alterations in endosomal trafficking, and $\mathrm{AD}$-like synapse alterations in $\mathrm{AD}$-transgenic neurons with time in culture, analogous to changes seen in vivo in $\mathrm{AD}$-transgenic mouse brains with aging (Takahashi et al., 2004; Almeida et al., 2005, 2006). In this study, we examined whether time in culture affects $A \beta$ secretion in $\mathrm{AD}$-transgenic neurons. In wild-type neurons, levels of secreted $\mathrm{A} \beta 1-40$ and $\mathrm{A} \beta 1-42$ remained unchanged between 12 and 19 DIV (Fig. 1A, left). In contrast, in $\mathrm{AD}$-transgenic neurons, levels of secreted $A \beta 1-40$ and $A \beta 1-42$ fell by $33 \pm 4 \%$ and $39 \pm 9 \%$, respectively, between 12 and 19 DIV (Fig. $1 A$, right). We next examined levels of intraneuronal $\mathrm{A} \beta$ with time in culture. There was a $46 \pm 17 \%$ increase in levels of intraneuronal $A \beta 42$ in $\mathrm{AD}$-transgenic neurites at 19 compared with 12 DIV, as quantified by confocal immunofluorescence microscopy (Fig. $1 B)$. In contrast, levels of intraneuronal $\mathrm{A} \beta 42$ were unchanged in wild-type neurons at 19 compared with $12 \mathrm{DIV}$ (Fig. 1C,D). 

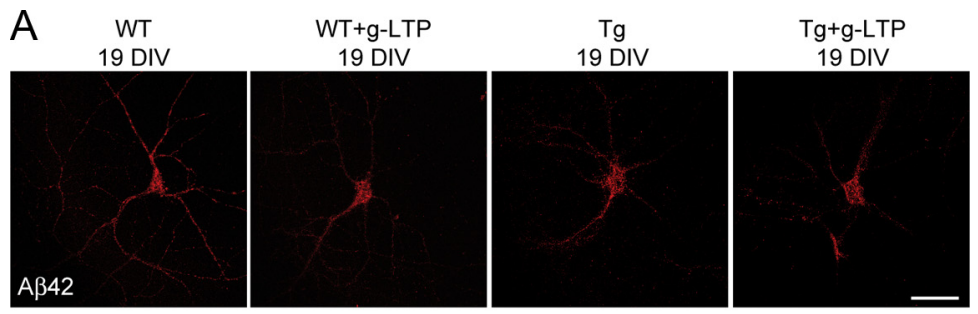

$\mathrm{B}$
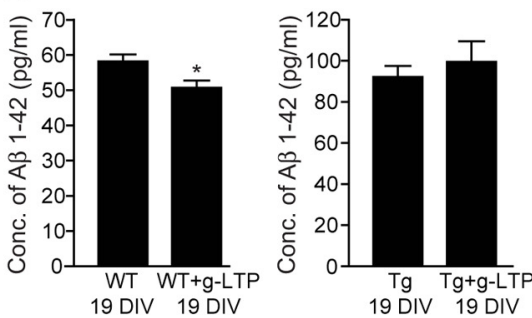

C

glycine

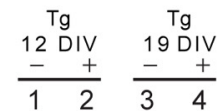

tubulin

$A \beta$

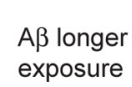

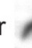
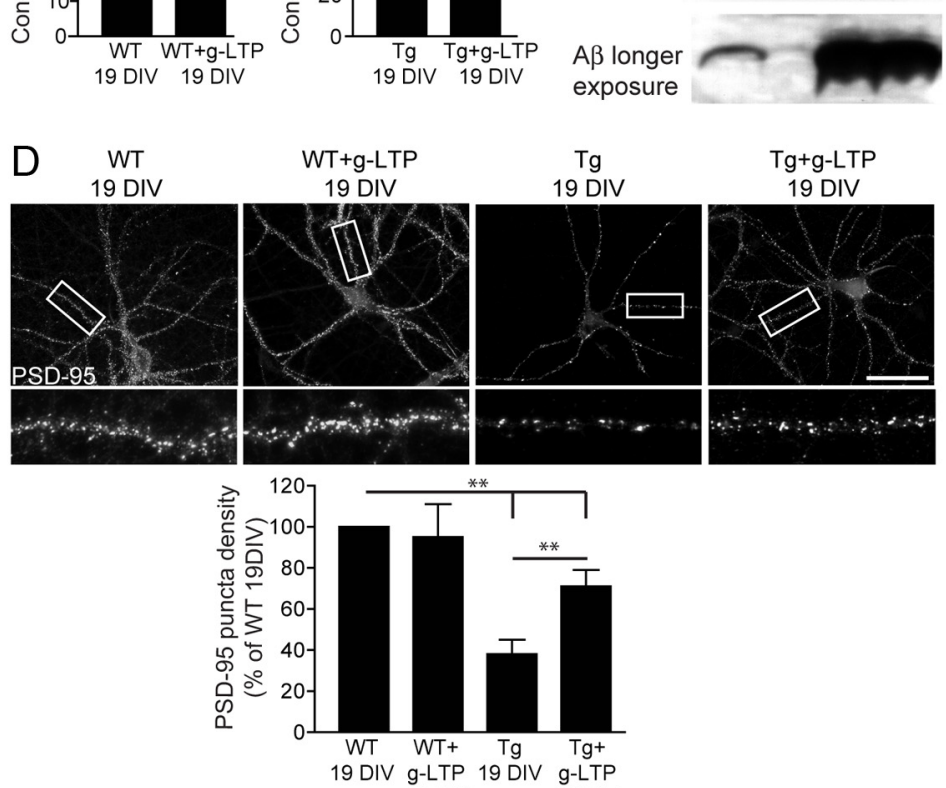

$E$
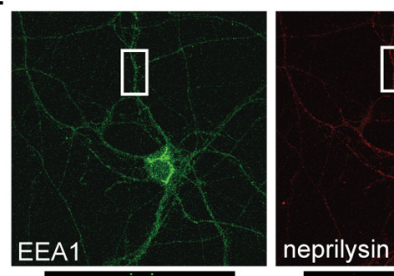

19 DIV
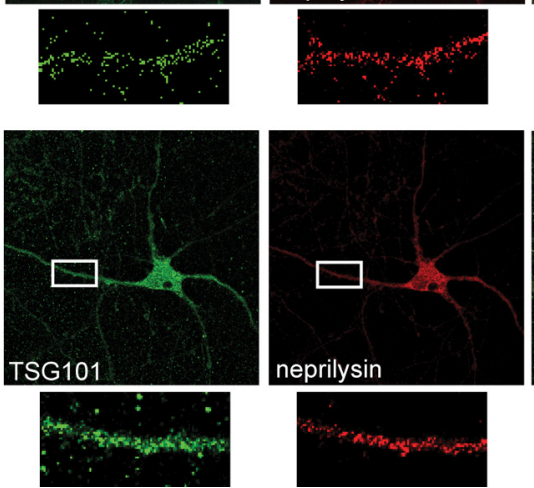

Figure 2. Impaired ability for synaptic activity to reduce intraneuronal $A \beta 42$ and protect synapses in AD-transgenic neurons with time in culture. $A, g$-LTP reduced levels of intraneuronal $A \beta 42$ by $23 \pm 4 \%$ in wild-type (WT; left) but not AD-transgenic (Tg; right) neurons at 19 DIV, as determined by confocal immunofluorescence $(n=4 ; p<0.01)$. $B, A \beta 1-42$ ELISA of lysates from $\mathrm{g}$-LTP compared with untreated neurons at 19 DIV revealed reduced levels of $A \beta 1-42$ in wild-type but not in AD-transgenic neurons $\left(n=4 ;{ }^{*} p<0.05\right.$ ). C, Western blot of cell lysates demonstrated reduced levels of intraneuronal A $\beta$ in $g$-LTP-treated compared with -untreated AD-transgenic neurons at 12 (lanes 1 and 2, longer exposure) but not 19 (lanes 3 and 4$)$ DIV $(n=3)$. D
Interestingly, the levels of APP $\alpha$ C-terminal fragments ( $\alpha$ CTFs) fell by $52 \pm 2 \%$ between 12 and $19 \mathrm{DIV}$ in $\mathrm{AD}$-transgenic neurons, whereas levels of APP $\beta$ C-terminal fragments $(\beta C T F s)$ and full-length APP remained unchanged (Fig. 1E, left). Thus, amyloidogenic processing of APP, as reflected by the $\beta \mathrm{CTF} / \alpha \mathrm{CTF}$ ratio, increased approximately twofold from 12 to 19 DIV in AD-transgenic neurons. Levels of $\alpha$ CTFs and $\beta C T F$ s were both comparably decreased in wild-type neurons at 19 compared with 12 DIV (Fig. $1 E$, right), and therefore the $\beta \mathrm{CTF} /$ $\alpha \mathrm{CTF}$ ratio did not change.

It has been shown that $\mathrm{A} \beta$ secretion is enhanced by synaptic activation (Kamenetz et al., 2003; Cirrito et al., 2005; Tampellini et al., 2009). Given the fall in steady-state secretion of $\mathrm{A} \beta$ in $\mathrm{AD}$-transgenic neurons with time in culture, we investigated whether $A \beta$ secretion was impaired during synaptic activity in $\mathrm{AD}$-transgenic neurons with time in culture. g-LTP was used to stimulate neurons (Ehlers, 2003) at 12 and 19 DIV followed by A $\beta$ ELISA of the conditioned media. We previously demonstrated that g-LTP increases $\mathrm{A} \beta$ secretion in $\mathrm{AD}$ transgenic neurons at $12 \mathrm{DIV}$ (Tampellini et al., 2009). We now show that, although g-LTP increases $A \beta$ secretion in wild-type neurons at $19 \mathrm{DIV}$, it failed to increase $\mathrm{A} \beta$ secretion in $\mathrm{AD}$-transgenic neurons at 19 DIV (Fig. $1 F$ ).

We reported that synaptic activation reduced intracellular $A \beta 42$ and restored levels of PSD-95 back to wild-type levels in ADtransgenic neurons at $12 \mathrm{DIV}$ (Tampellini et al., 2009). To investigate whether these effects are modulated by aging in vitro, we induced g-LTP in 19 DIV AD-transgenic neurons and quantified levels of intraneuronal $\mathrm{A} \beta$ and PSD-95. At 19 DIV, g-LTP reduced levels of intraneuronal $\mathrm{A} \beta 42$ by $23 \pm 4 \%$ in wild-type neurons, but there was no decrease in $\mathrm{AD}$-transgenic neurons as determined by confocal immunofluorescence (Fig. 2A). These data were confirmed by ELISA (Fig. $2 B$ ) and Western blot (Fig. $2 C$ ) of neuronal lysates. We confirmed that 12 DIV lysates showed decreased levels of intraneuronal $\mathrm{A} \beta$ in g-LTP-treated compared with -untreated $\mathrm{AD}$-transgenic neurons (Fig. 2C; lanes 1 and 2, longer ex-

PSD-95 puncta increased in g-LTP-activated AD-transgenic neurons at 19 DIV, although they failed to reach wild-type levels ( $n=5{ }^{* *} p<0.01$ ). $\boldsymbol{E}$, Wild-type neurons (12 DIV) showed a $74 \pm 21 \%$ greater relative colocalization of neprilysin with the MVB/late endosomal marker tumor susceptibility gene 101 (TSG101) than the early endosomal marker early endosomal antigen-1 (EEA1) ( $n=3 ; p<0.01)$. Conc., Concentration. Scale bars: $\boldsymbol{A}, \boldsymbol{D}, \boldsymbol{E}, 50 \mu \mathrm{m} ; \boldsymbol{E}$, inset, $10 \mu \mathrm{m}$. 

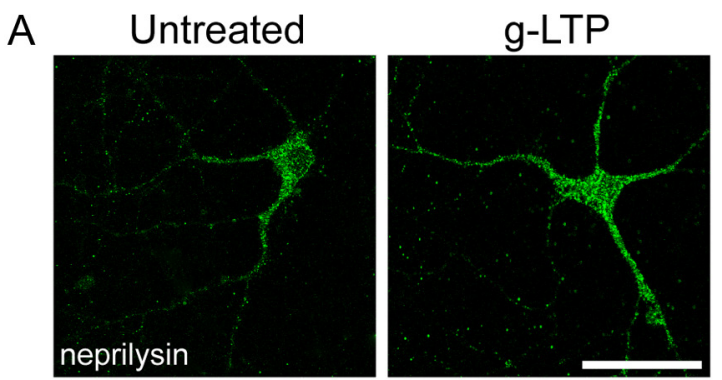

$\mathrm{B}$
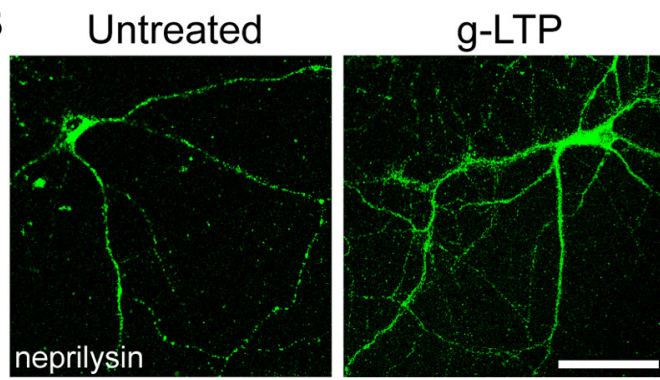

C

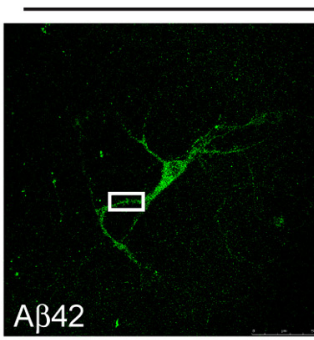

Untreated
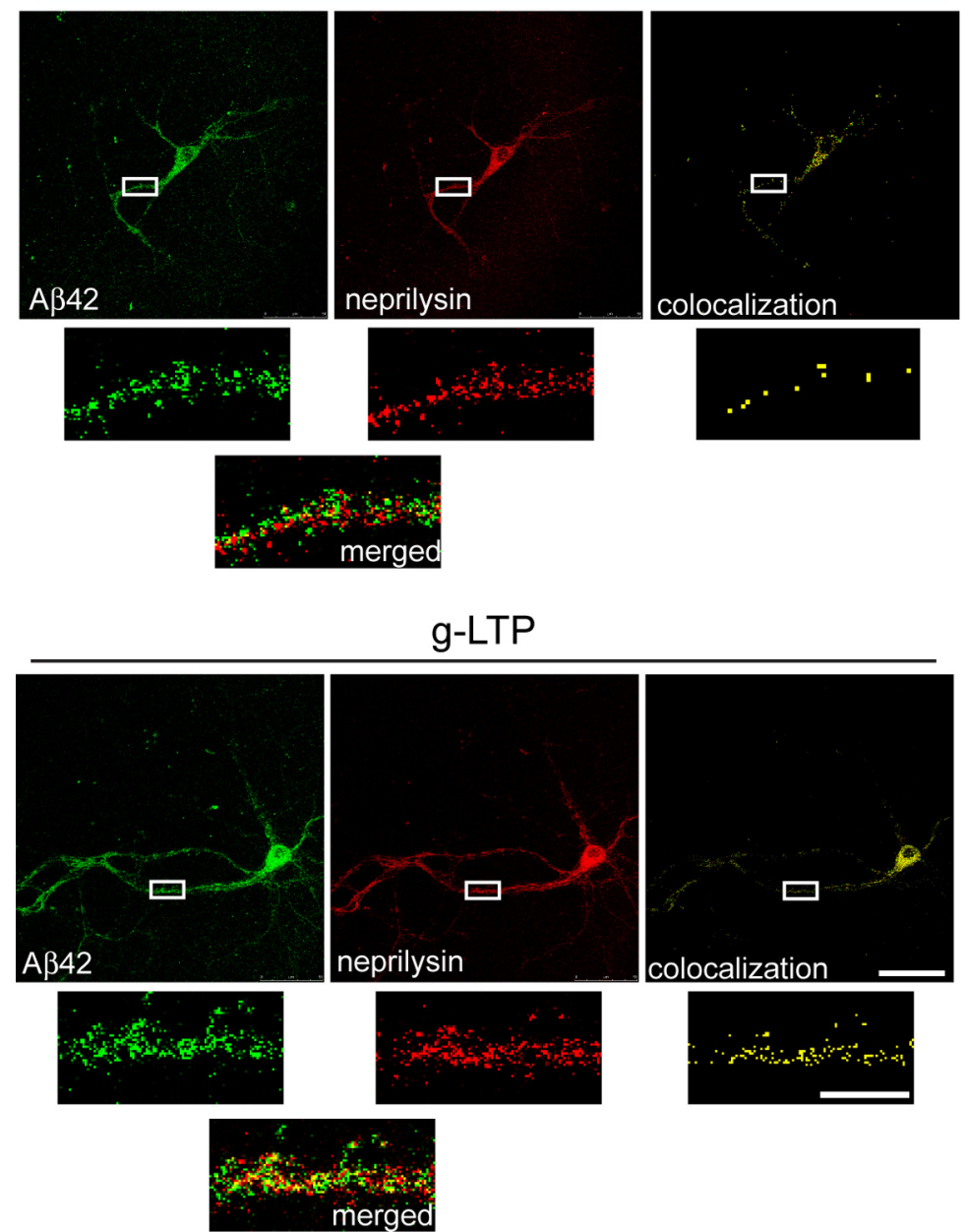

Figure 3. Synaptic activation increases neprilysin surface levels and colocalization with $A \beta 42 . \boldsymbol{A}, \mathrm{g}$-LTP increased levels of surface neprilysin by $37 \pm 7 \%$ in $\mathrm{g}$-LTP-treated compared with -untreated wild-type neurons at 12 DIV $(n=6 ; p<$ 0.01). $B, g$-LTP also increased levels of surface neprilysin in g-LTP-treated compared with untreated AD-transgenic neurons at 12 DIV $(n=3 ; p<0.01) . C, g$-LTP increased the relative colocalization of neprilysin with A $\beta 42$ by $54 \pm 21 \%$ at the cell surface in AD-transgenic neurons at 12 DIV $(n=3 ; p<0.01)$. Scale bars: $\boldsymbol{A}-\boldsymbol{C}, 50 \mu \mathrm{m} ; \boldsymbol{C}$, insets, $10 \mu \mathrm{m}$. posure). Activity-induced reduction in levels of intraneuronal $\mathrm{A} \beta$ promoted recovery of PSD-95 puncta to wild-type levels in ADtransgenic neurons at 12 DIV (Tampellini et al., 2009). In contrast, levels of PSD-95 did not recover back to wild-type levels in g-LTP-treated compared with -untreated 19 DIV AD-transgenic neurons (Fig. 2D), although there was still an increase compared with untreated $\mathrm{AD}$-transgenic neurons.

We showed that activity-dependent reduction in intraneuronal $A \beta$ is dependent on the $A \beta$-degrading protease neprilysin (Tampellini et al., 2009). Data on the subcellular localization of neprilysin showed marked relative colocalization of neprilysin predominantly with late endosomes (Fig. 2E). To investigate the mechanism of neprilysin-dependent $A \beta 42$ clearance with synaptic activity, levels of neprilysin were quantified as a function of synaptic activation. g-LTP did not change total levels of neprilysin (data not shown); however, it did increase levels of surface neprilysin by $37 \pm 7 \%$ in stimulated compared with unstimulated wild-type neurons (Fig. 3A). Surface neprilysin also increased in stimulated compared with nonstimulated $\mathrm{AD}$-transgenic neurons (Fig. $3 B)$. We next explored whether the increased localization of neprilysin to the cell surface could be responsible for the augmented neprilysin-dependent A $\beta 42$ degradation. To test this hypothesis, g-LTP was induced in $\mathrm{AD}$-transgenic neurons in the presence of the neprilysin inhibitor thiorphan to prevent loss of $A \beta 42$ labeling from degradation. g-LTP increased the relative colocalization of neprilysin with $\mathrm{A} \beta 42$ at the cell surface by $54 \pm 21 \%$ (Fig. 3C).

Since synaptic activation failed to reduce levels of intraneuronal $\mathrm{A} \beta$ in $\mathrm{AD}$-transgenic neurons at $19 \mathrm{DIV}$, we next investigated whether levels of neprilysin were altered in $\mathrm{AD}$-transgenic neurons with time in culture. Remarkably, levels of neprilysin were decreased by $18 \pm 8 \%$ in 19 compared with 12 DIV AD-transgenic but not wild-type neurons, as quantified by confocal immunofluorescence (Fig. 4A). Previous work reported that neprilysin is regulated by the AICD (Pardossi-Piquard et al., 2005). To investigate whether reduction of neprilysin might be related to reduced levels of AICD in the nucleus with time in culture, we double-labeled nuclei of 12 and 19DIV ADtransgenic neurons with Hoechst stain and an AICD-specific antibody. Remarkably, the number of AICD-positive nuclei was decreased by $27 \pm 6 \%$ in 19 compared with 12 DIV AD-transgenic neurons (Fig. $4 B$ ), suggesting reduced synthesis of neprilysin with time in culture. 


\section{Discussion}

The data presented here provide evidence for an impaired ability of familial ADtransgenic neurons to efficiently modulate levels of secreted and intraneuronal $\mathrm{A} \beta$ with time in culture. We demonstrate that the ability to secrete $A \beta$ falls with time in culture in $\mathrm{AD}$-transgenic but not wild-type neurons. Activity-induced $\mathrm{A} \beta$ secretion also falls with time in culture in $\mathrm{AD}$-transgenic but not wild-type neurons. Moreover, with time in culture, $\mathrm{AD}$ transgenic neurons become impaired in their ability to reduce intracellular $A \beta$ and protect synapses in response to synaptic activity. We provide evidence that the mechanism by which synaptic activity reduces intracellular $A \beta 42$ is dependent on the $A \beta$-degrading protease neprilysin. Synaptic activity leads to recruitment of neprilysin to the cell surface and increased colocalization with $A \beta 42$. Finally, we show that neprilysin levels fall with time in culture in AD-transgenic but not wild-type neurons, providing a mechanism for the failure of synaptic activation to reduce intracellular $\mathrm{A} \beta$ in aged $\mathrm{AD}$ transgenic neurons (Fig. $4 C, D$ ).

These data have important implications for $\mathrm{AD}$. Decreased neuronal secretion of $\mathrm{A} \beta$ with aging in $\mathrm{AD}$ could explain previous data that baseline interstitial $\mathrm{A} \beta 42$ levels appear to be reduced in older compared with younger $\mathrm{AD}$-transgenic mice (Cirrito et al., 2005). Reduced $A \beta 42$ levels are also seen in CSF in human $\mathrm{AD}$, even in subjects who are cognitively normal but later develop $\mathrm{AD}$ (Fagan et al., 2009). The traditional explanation for reduced CSF $A \beta 42$ with $\mathrm{AD}$ is that secreted $A \beta$ is decreased by sequestration to extracellular plaques. Decreased secretion would also contribute to reduced $\mathrm{A} \beta 42 \mathrm{lev}$ els in CSF or interstitial fluid. Of note, other pathological conditions linked with $\mathrm{AD}$, such as brain injury, also show reduced levels of extracellular $\mathrm{A} \beta$ (Brody et al., 2008) and increased intraneuronal $\mathrm{A} \beta$ (Gouras et al., 2010).

Reduced $\mathrm{A} \beta$ secretion fits well with increasing evidence for early intraneuronal $\mathrm{A} \beta$ accumulation with $\mathrm{AD}$ pathogenesis, as reported in human $\mathrm{AD}$, Down syndrome, and in $\mathrm{AD}$-transgenic rodents (Gouras et al., 2000; D'Andrea et al., 2001; Wirths et al., 2001; Takahashi et al., 2002; Oddo et al., 2003; Cataldo et al., 2004; Echeverria et al., 2004; Lord et al., 2006; Oakley et al., 2006; Knobloch et al., 2007; Gandy et al., 2010). Intraneuronal $A \beta$ accumulates and oligomerizes preferentially in distal processes even before plaques (Takahashi et al., 2004), and is associated with memory impairment, decreased synaptic plasticity, and subcellular pathology (Mori et al., 2002; Takahashi et al.,
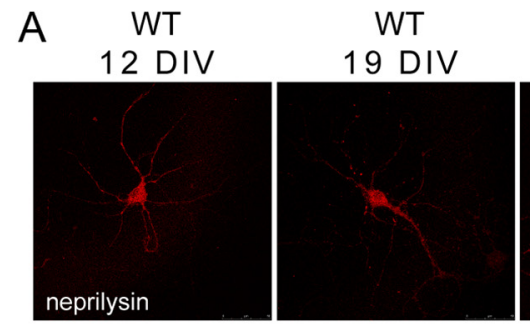

$\mathrm{Tg}$ 12 DIV
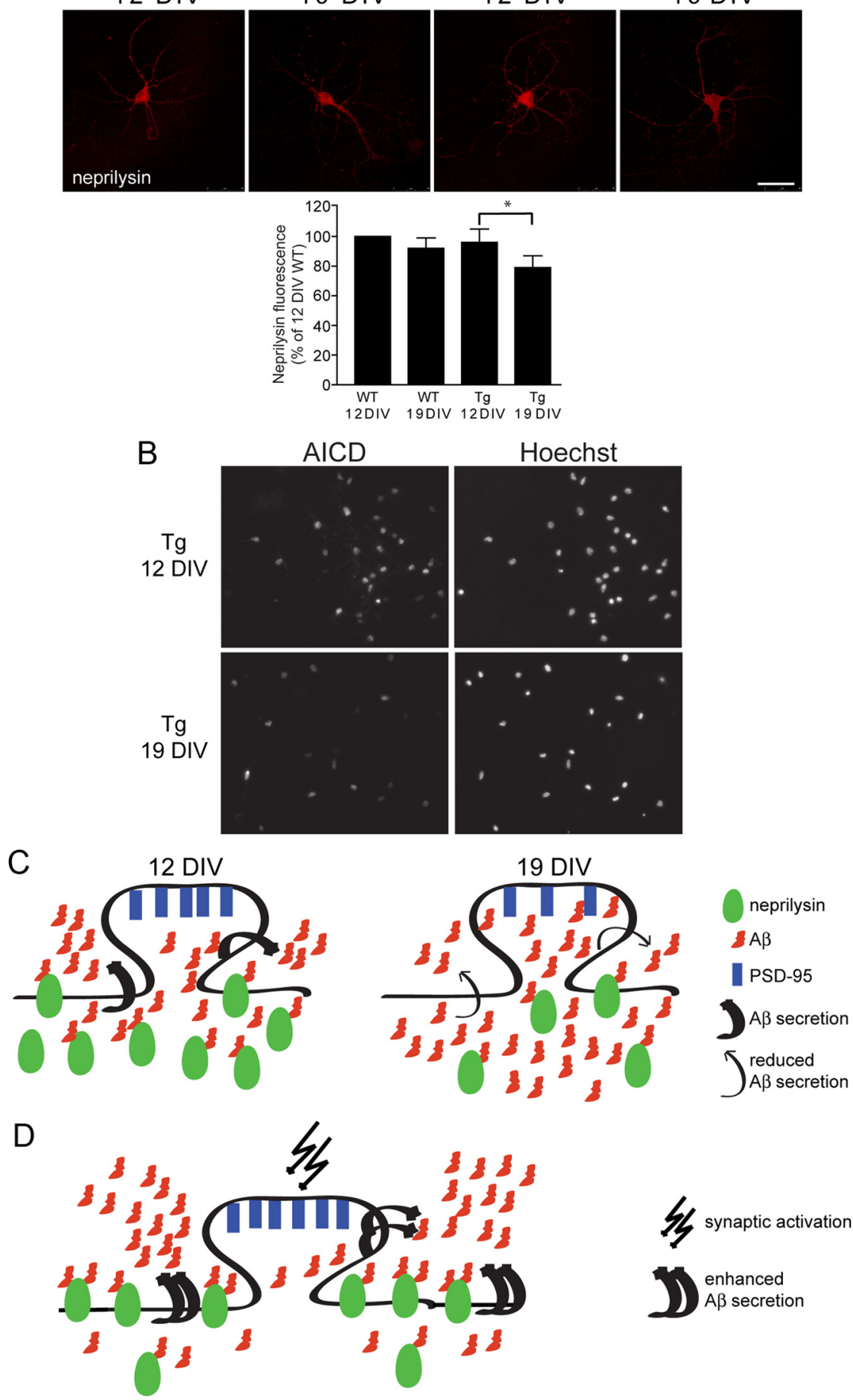

Figure 4. Decreased levels of neprilysin in AD-transgenic neurons with time in culture. $A$, Levels of neprilysin were decreased by $18 \pm 8 \%$ in 19 compared with 12 DIV AD-transgenic neurons $\left(n=4 ;{ }^{*} p<0.05\right.$; scale bar, $\left.50 \mu \mathrm{m}\right)$. In contrast, 19 compared with 12 DIV wild-type neurons did not show a decrease of neprilysin. $B$, The number of AICD-positive nuclei was decreased by $27 \pm 6 \%$ in 19 compared with 12 DIV AD-transgenic neurons $(n=3 ; p<0.05)$. C, The ability to secrete $A \beta$ falls with time in culture in $A D$-transgenic neurons. Neprilysin levels fall with time in culture, suggesting a mechanism for progressive intracellular $A \beta$ accumulation and loss of synaptic proteins (PSD-95) in aged AD-transgenic neurons. D, Synaptic activity enhances A $\beta$ secretion, leads to neprilysin recruitment to the cell surface, and increases colocalization of neprilysin with $A \beta 42$.

2002; Oddo et al., 2003; Almeida et al., 2005; Billings et al., 2005; Tomiyama et al., 2010). Intraneuronal A $\beta 42$ localizes and accumulates preferentially in late endosomes, including multivesicular bodies (MVBs) (Takahashi et al., 2002; Langui et al., 2004; Almeida et al., 2006). Interestingly, neprilysin also localizes to late endosomes/ 
MVBs (Fig. 2E). We show that neprilysin significantly relocates to the cell surface during synaptic activation. Neprilysin is a transmembrane neutral endopeptidase with the catalytic site at the $\mathrm{C}$ terminal side, which can be either extracellular or luminal. Since neprilysin works best at neutral $\mathrm{pH}$, the cell surface would be the optimal location for it to degrade $A \beta 42$. In fact, we observed that colocalization of neprilysin and $A \beta 42$ was increased at the cell surface with synaptic activation. This pool of A $\beta 42$ could derive from amyloidogenic APP processing occurring within synaptic endosomes with synaptic activity (Cirrito et al., 2008; Tampellini et al., 2009), followed by trafficking of $A \beta$ to the cell surface (Rajendran et al., 2006). The finding that neprilysin normally declines with aging in synaptic layers of wild-type mouse brain (Iwata et al., 2002) supports the theory that it plays a critical role in synaptic accumulation of $\mathrm{A} \beta$ with aging and $\mathrm{AD}$. We show that neprilysin is reduced in $\mathrm{AD}$-transgenic but not wild-type neurons with time in culture, although it is possible that a decline would eventually occur later in wild-type neurons. Reduced neprilysin in $\mathrm{AD}$-transgenic neurons with time in culture can explain the impaired ability to reduce intraneuronal $\mathrm{A} \beta$, in particular $\mathrm{A} \beta 42$, with synaptic activity, since we previously reported the inability of synaptic activity to reduce $A \beta 42$ in neprilysin knock-out neurons or when neprilysin activity was blocked by treatment with thiorphan (Tampellini et al., 2009). In addition, it has been shown that extracellular $\mathrm{A} \beta$ can upregulate intracellular $\mathrm{A} \beta$ (Yang et al., 1999; Tampellini et al., 2009), which could lead to a vicious cycle of $\mathrm{A} \beta$-induced elevation and synapse damage.

Overall, this study provides novel evidence for reduced $\mathrm{A} \beta$ secretion and impaired ability to reduce intraneuronal $A \beta$ with time in culture in AD-transgenic neurons, and further underscores the important role of neprilysin in regulating neuronal $\mathrm{A} \beta$.

\section{References}

Almeida CG, Tampellini D, Takahashi RH, Greengard P, Lin MT, Snyder EM, Gouras GK (2005) Beta-amyloid accumulation in APP mutant neurons reduces PSD-95 and GluR1 in synapses. Neurobiol Dis 20:187-198.

Almeida CG, Takahashi RH, Gouras GK (2006) Beta-amyloid accumulation impairs multivesicular body sorting by inhibiting the ubiquitinproteasome system. J Neurosci 26:4277-4288.

Billings LM, Oddo S, Green KN, McGaugh JL, LaFerla FM (2005) Intraneuronal Abeta causes the onset of early Alzheimer's disease-related cognitive deficits in transgenic mice. Neuron 45:675-688.

Brody DL, Magnoni S, Schwetye KE, Spinner ML, Esparza TJ, Stocchetti N, Zipfel GJ, Holtzman DM (2008) Amyloid-beta dynamics correlate with neurological status in the injured human brain. Science 321:1221-1224.

Cataldo AM, Petanceska S, Terio NB, Peterhoff CM, Durham R, Mercken M, Mehta PD, Buxbaum J, Haroutunian V, Nixon RA (2004) Abeta localization in abnormal endosomes: association with earliest Abeta elevations in AD and Down syndrome. Neurobiol Aging 25:1263-1272.

Cirrito JR, Yamada KA, Finn MB, Sloviter RS, Bales KR, May PC, Schoepp DD, Paul SM, Mennerick S, Holtzman DM (2005) Synaptic activity regulates interstitial fluid amyloid-beta levels in vivo. Neuron 48:913-922.

Cirrito JR, Kang JE, Lee J, Stewart FR, Verges DK, Silverio LM, Bu G, Mennerick S, Holtzman DM (2008) Endocytosis is required for synaptic activity-dependent release of amyloid-beta in vivo. Neuron 58:42-51.

Cleary JP, Walsh DM, Hofmeister JJ, Shankar GM, Kuskowski MA, Selkoe DJ, Ashe KH (2005) Natural oligomers of the amyloid-beta protein specifically disrupt cognitive function. Nat Neurosci 8:79-84.

D'Andrea MR, Nagele RG, Wang HY, Peterson PA, Lee DH (2001) Evidence that neurones accumulating amyloid can undergo lysis to form amyloid plaques in Alzheimer's disease. Histopathology 38:120-134.

Echeverria V, Ducatenzeiler A, Dowd E, Jänne J, Grant SM, Szyf M, Wandosell F, Avila J, Grimm H, Dunnett SB, Hartmann T, Alhonen L, Cuello AC (2004) Altered mitogen-activated protein kinase signaling, tau hyperphosphorylation and mild spatial learning dysfunction in transgenic rats expressing the beta-amyloid peptide intracellularly in hippocampal and cortical neurons. Neuroscience 129:583-592.

Ehlers MD (2003) Activity level controls postsynaptic composition and signaling via the ubiquitin-proteasome system. Nat Neurosci 6:231-242.
Fagan AM, Head D, Shah AR, Marcus D, Mintun M, Morris JC, Holtzman DM (2009) Decreased cerebrospinal fluid Abeta(42) correlates with brain atrophy in cognitively normal elderly. Ann Neurol 65:176-183.

Gandy S, Simon AJ, Steele JW, Lublin AL, Lah JJ, Walker LC, Levey AI, Krafft GA, Levy E, Checler F, Glabe C, Bilker WB, Abel T, Schmeidler J, Ehrlich ME (2010) Days to criterion as an indicator of toxicity associated with human Alzheimer amyloid-beta oligomers. Ann Neurol 68:220-230.

Gouras GK, Tsai J, Naslund J, Vincent B, Edgar M, Checler F, Greenfield JP, Haroutunian V, Buxbaum JD, Xu H, Greengard P, Relkin NR (2000) Intraneuronal Abeta42 accumulation in human brain. Am J Pathol 156:15-20.

Gouras GK, Tampellini D, Takahashi RH, Capetillo-Zarate E (2010) Intraneuronal beta-amyloid accumulation and synapse pathology in Alzheimer's disease. Acta Neuropathol 119:523-541.

Hsiao K, Chapman P, Nilsen S, Eckman C, Harigaya Y, Younkin S, Yang F, Cole G (1996) Correlative memory deficits, Abeta elevation, and amyloid plaques in transgenic mice. Science 274:99-102.

Hsieh H, Boehm J, Sato C, Iwatsubo T, Tomita T, Sisodia S, Malinow R (2006) AMPAR removal underlies Abeta-induced synaptic depression and dendritic spine loss. Neuron 52:831-843.

Iwata N, Takaki Y, Fukami S, Tsubuki S, Saido TC (2002) Region-specific reduction of A beta-degrading endopeptidase, neprilysin, in mouse hippocampus upon aging. J Neurosci Res 70:493-500.

Kamenetz F, Tomita T, Hsieh H, Seabrook G, Borchelt D, Iwatsubo T, Sisodia S, Malinow R (2003) APP processing and synaptic function. Neuron 37:925-937.

Knobloch M, Konietzko U, Krebs DC, Nitsch RM (2007) Intracellular Abeta and cognitive deficits precede beta-amyloid deposition in transgenic arcAbeta mice. Neurobiol Aging 28:1297-1306.

Langui D, Girardot N, El Hachimi KH, Allinquant B, Blanchard V, Pradier L, Duyckaerts C (2004) Subcellular topography of neuronal Abeta peptide in APPxPS1 transgenic mice. Am J Pathol 165:1465-1477.

Lord A, Kalimo H, Eckman C, Zhang XQ, Lannfelt L, Nilsson LN (2006) The arctic Alzheimer mutation facilitates early intraneuronal Abeta aggregation and senile plaque formation in transgenic mice. Neurobiol Aging 27:67-77.

Mori C, Spooner ET, Wisniewsk KE, Wisniewski TM, Yamaguch H, Saido TC, Tolan DR, Selkoe DJ, Lemere CA (2002) Intraneuronal Abeta42 accumulation in Down syndrome brain. Amyloid 9:88-102.

Oakley H, Cole SL, Logan S, Maus E, Shao P, Craft J, Guillozet-Bongaarts A, Ohno M, Disterhoft J, Van Eldik L, Berry R, Vassar R (2006) Intraneuronal beta-amyloid aggregates, neurodegeneration, and neuron loss in transgenic mice with five familial Alzheimer's disease mutations: potential factors in amyloid plaque formation. J Neurosci 26:10129-10140.

Oddo S, Caccamo A, Shepherd JD, Murphy MP, Golde TE, Kayed R, Metherate R, Mattson MP, Akbari Y, LaFerla FM (2003) Triple-transgenic model of Alzheimer's disease with plaques and tangles: intracellular Abeta and synaptic dysfunction. Neuron 39:409-421.

Palop JJ, Mucke L (2010) Amyloid-beta-induced neuronal dysfunction in Alzheimer's disease: from synapses toward neural networks. Nat Neurosci 13:812-818.

Pardossi-Piquard R, Petit A, Kawarai T, Sunyach C, Alves da Costa C, Vincent B, Ring S, D’Adamio L, Shen J, Müller U, St George Hyslop P, Checler F (2005) Presenilin-dependent transcriptional control of the Abetadegrading enzyme neprilysin by intracellular domains of betaAPP and APLP. Neuron 46:541-554.

Puzzo D, Privitera L, Leznik E, Fà M, Staniszewski A, Palmeri A, Arancio O (2008) Picomolar amyloid-beta positively modulates synaptic plasticity and memory in hippocampus. J Neurosci 28:14537-14545.

Rajendran L, Honsho M, Zahn TR, Keller P, Geiger KD, Verkade P, Simons K (2006) Alzheimer's disease beta-amyloid peptides are released in association with exosomes. Proc Natl Acad Sci U S A 103:11172-11177.

Reiman EM, Chen K, Alexander GE, Caselli RJ, Bandy D, Osborne D, Saunders AM, Hardy J (2004) Functional brain abnormalities in young adults at genetic risk for late-onset Alzheimer's dementia. Proc Natl Acad Sci U S A 101:284-289.

Selkoe DJ (2002) Alzheimer's disease is a synaptic failure. Science 298:789-791.

Shankar GM, Li S, Mehta TH, Garcia-Munoz A, Shepardson NE, Smith I, Brett FM, Farrell MA, Rowan MJ, Lemere CA, Regan CM, Walsh DM, 
Sabatini BL, Selkoe DJ (2008) Amyloid-beta protein dimers isolated directly from Alzheimer's brains impair synaptic plasticity and memory. Nat Med 14:837-842.

Takahashi RH, Milner TA, Li F, Nam EE, Edgar MA, Yamaguchi H, Beal MF, $\mathrm{Xu} \mathrm{H}$, Greengard P, Gouras GK (2002) Intraneuronal Alzheimer abeta42 accumulates in multivesicular bodies and is associated with synaptic pathology. Am J Pathol 161:1869-1879.

Takahashi RH, Almeida CG, Kearney PF, Yu F, Lin MT, Milner TA, Gouras GK (2004) Oligomerization of Alzheimer's beta-amyloid within processes and synapses of cultured neurons and brain. J Neurosci 24:3592-3599.

Tampellini D, Rahman N, Gallo EF, Huang Z, Dumont M, Capetillo-Zarate E, Ma T, Zheng R, Lu B, Nanus DM, Lin MT, Gouras GK (2009) Synaptic activity reduces intraneuronal Abeta, promotes APP transport to synapses, and protects against Abeta-related synaptic alterations. J Neurosci 29:9704-9713.

Tampellini D, Capetillo-Zarate E, Dumont M, Huang Z, Yu F, Lin MT, Gou- ras GK (2010) Effects of synaptic modulation on beta-amyloid, synaptophysin, and memory performance in Alzheimer's disease transgenic mice. J Neurosci 30:14299-14304.

Tomiyama T, Matsuyama S, Iso H, Umeda T, Takuma H, Ohnishi K, Ishibashi K, Teraoka R, Sakama N, Yamashita T, Nishitsuji K, Ito K, Shimada H, Lambert MP, Klein WL, Mori H (2010) A mouse model of amyloid \{beta\} oligomers: their contribution to synaptic alteration, abnormal tau phosphorylation, glial activation, and neuronal loss in vivo. J Neurosci 30:4845-4856.

Wirths O, Multhaup G, Czech C, Blanchard V, Moussaoui S, Tremp G, Pradier L, Beyreuther K, Bayer TA (2001) Intraneuronal Abeta accumulation precedes plaque formation in beta-amyloid precursor protein and presenilin-1 double-transgenic mice. Neurosci Lett 306:116-120.

Yang AJ, Chandswangbhuvana D, Shu T, Henschen A, Glabe CG (1999) Intracellular accumulation of insoluble, newly synthesized abetan- 42 in amyloid precursor protein-transfected cells that have been treated with Abeta1-42. J Biol Chem 274:20650-20656. 